\title{
On the Structural Properties of Voronoi Diagrams
}

\section{On the Structural Properties of Voronoi Diagrams}

\section{ABSTRACT}

A Voronoi diagram is a tessellation technique, which subdivides space into regions in proximity to a given set of objects called seeds. Patterns emerging naturally in biological processes (for example, in cell tissue) can be modelled in a biomimicry process via Voronoi diagrams. As they originate in nature, we investigate the physical properties of such patterns to determine whether they are optimal given the constraints imposed by surrounding geometry and natural forces.

This paper describes under what circumstances the Voronoi tessellation has optimal (structural) properties by surveying recent studies that apply this tessellation technique across different scales. To investigate the properties of random and optimized Voronoi tessellations in comparison to a regular tessellation method, we additionally run and evaluate a simulation in Karamba3D, a parametric structural engineering tool for Rhinoceros3D.

The novelty of this research lies in presenting a simple and straightforward simulation of Voronoi diagrams and highlighting how and where their advantages over regular tessellations can be exploited by surveying more advanced approaches as found in literature.

Key words: Voronoi diagrams, 3D tessellations, 3D scaffolds

MSC2010: 51-02, 52C25, 05B45

\section{Introduction}

Figure 1 shows some example patterns found in nature next to a two-dimensional Voronoi diagram, exemplifying the resemblance between some naturally arising patterns and Voronoi tessellation. Since these patterns arise naturally

\section{O strukturalnim svojstvima Voronoi dijagrama}

\section{SAŽETAK}

Voronoi dijagram je tehnika popločavanja koja čini particiju prostora $s$ obzirom na udaljenosti od zadanog skupa objekata koje nazivamo lokacije (en. seeds). Uzorke koji nastaju tokom bioloških procesa (na primjer u staničnom tkivu) možemo modelirati biomimikrijskim procesima korištenjem Voronoi dijagrama. Kako je izvor takvih struktura prirodan, proučavamo fizička svojstva takvih uzoraka da bismo ispitali njihovu optimalnost s obzirom na ograničenja koja nameću vanjska geometrija i prirodne sile.

U ovom članku opisujemo slučajeve u kojima je Voronoi popločavanje (strukturalno) optimalno proučavanjem nedavnih ispitivanja koja ovo popločavanje koriste u različitim razmjerima. Da bismo usporedili svojstva slučajnog te optimiziranog Voronoi popločavanja i metode pravilnog popločavanja, razvili smo simulaciju korištenjem Karamba3D, alata za parametarsko strukturalno inženjersko modeliranje unutar programa Rhinoceros3D.

Novost ovog istraživanja je predstavljanje jednostavne i izravne simulacije Voronoi dijagrama, isticanje njenih prednosti nad pravilnim popločavanjima te pregled korištenja tih prednosti u naprednijim pristupima iz literature.

Ključne riječi: Voronoi dijagrami, 3D popločavanja, 3D konstrukcije

we ask ourselves if there is a reason for this occurrence. If this pattern developed through evolution, there might be some properties that are optimal under constraints imposed by geometry and natural forces. To this end we first created a three-dimensional Voronoi diagram in Grasshopper and investigated its structural properties using the Karamba3D 


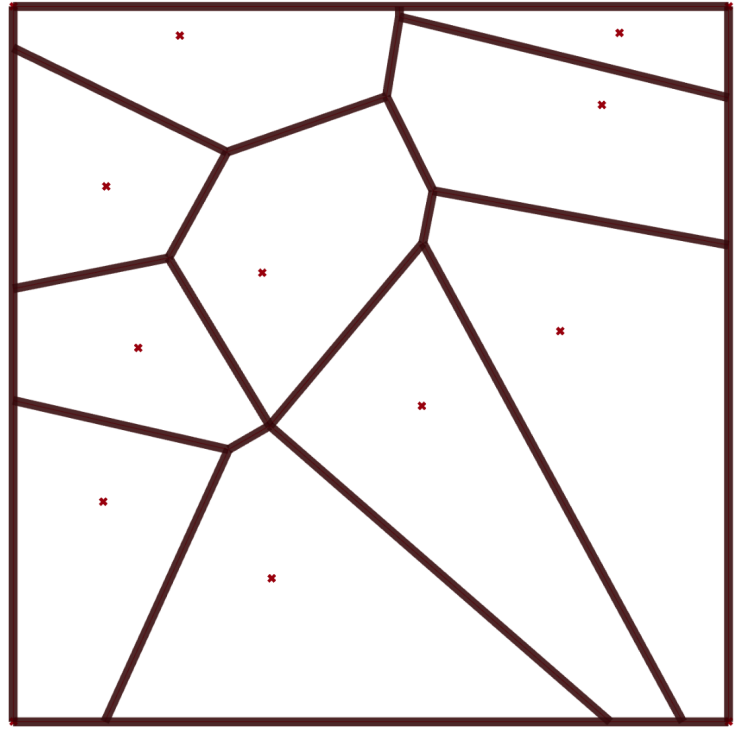

(a)

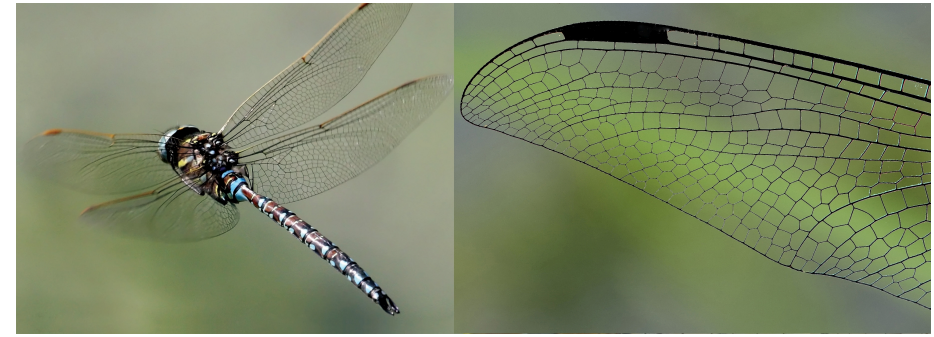

(b)
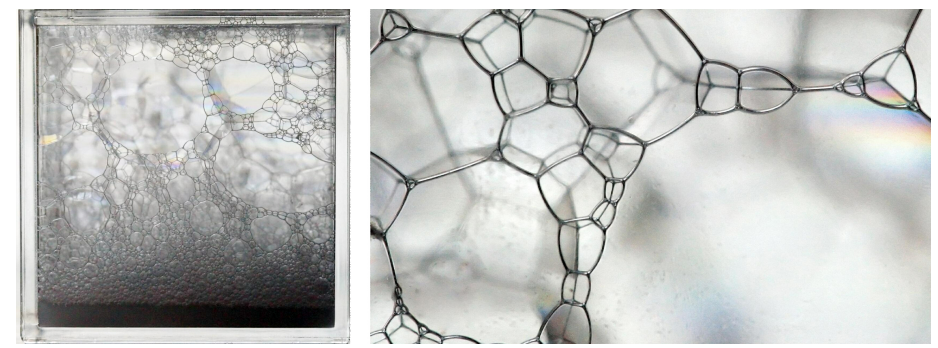

Figure 1: (a) shows a two-dimensional Voronoi diagram within a square boundary. (b) shows a similar pattern found in dragonfly wings. (c) shows foam in a transparent cube, after it has settled, displaying a Voronoi-like pattern 1 .

[10] plugin, a structural engineering tool. We do this by creating random Voronoi tessellations of a cube. We compare this to a regular triangle mesh tessellation. Since evolution is an optimization process, we further test a model of a Voronoi tessellation which is optimized in terms of weight and elastic energy of the structure using Octopus [11], which employs a genetic algorithm. We then research relevant literature which employs Voronoi diagrams and exploit its properties in some way. The paper is structured as follows: In Section 2 we discuss the definition and creation of a Voronoi diagram. Section 3 compares random and optimized Voronoi tessellations of a cube with a regular triangle mesh under load. We survey relevant literature on methods where the properties of Voronoi diagrams can be exploited in Section 4. Finally, we give our closing remarks on how and when Voronoi diagrams can be utilized in Section 5 .

\section{Background}

The Voronoi diagram describes a partition of space into regions surrounding a number of seed points. The definition below follows the one found in [1]. For the twodimensional case, let $S$ be the set of $n$ seed-points. The dominance of a seed $p$ over $q, p, q \in S$, is defined as

$\operatorname{dom}(p, q)=\{x \in \mathbb{R} \mid \boldsymbol{\delta}(x, p) \leq \boldsymbol{\delta}(x, q)\}$.

Here, $\delta$ describes the Euclidean distance. This can be adapted for higher dimensions and other metrics. A result

\footnotetext{
${ }^{1}$ Photographs (c) Georg Glaeser, with permission.
}

of this is the partitioning of space into points lying closer to $p$ or $q$, creating regions per seed $p$ where portions of the plane lie in all of the dominances of $p$ over remaining seeds in $S$. Formally, this means

$\operatorname{reg}(p)=\bigcap_{q \in S-p} \operatorname{dom}(p, q)$.

For each region, the boundary consists of at most $n-1$ edges and vertices, the endpoints of the edges. The points lying on an edge are equidistant from exactly two seeds. The vertices are equidistant from at least three. Thus, the regions form a polygonal partition of the plane, which is called the Voronoi diagram. For a large number of seeds, the Voronoi diagram converges towards a hexagonal pattern [2]. The Voronoi diagram is named for GEORGY F. VORONOY, who investigated the n-dimensional case in 1908 [12].

\section{Simulation of a 3D Voronoi structure un- der load}

Using Karamba3D [10], a structural engineering tool, we modelled three structures within a cube: a random Voronoi tessellation, a regular triangle mesh tessellation, and an optimized Voronoi tessellation. We use built-in components of Grasshopper to model the Voronoi structure which in turn is used as input for the Karamba3D model. Karamba3D transforms the Voronoi structure into beams which together with supports and loads are assembled into 


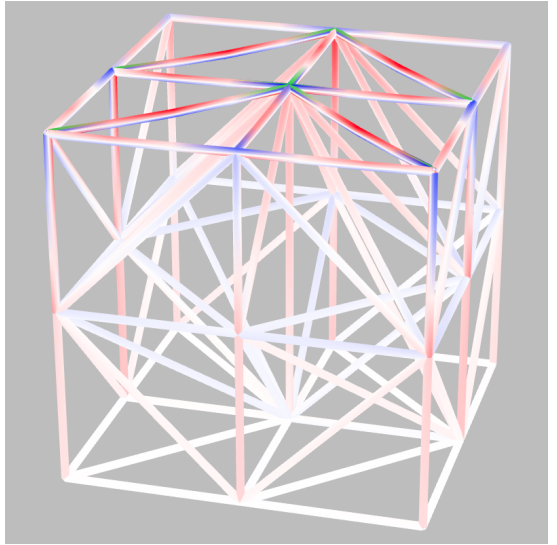

(a) Triangle mesh tessellation

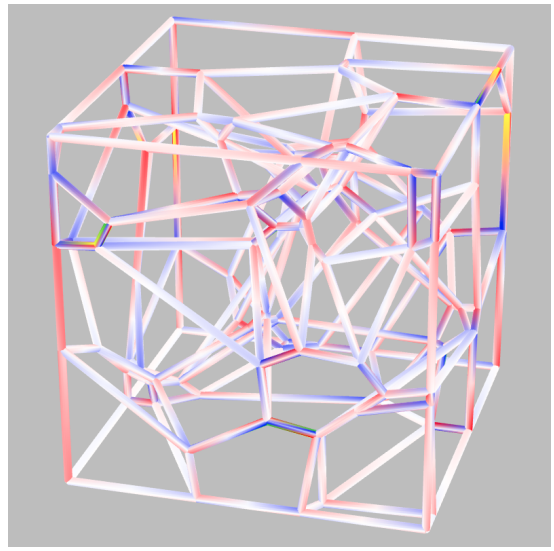

(b) Random Voronoi tessellation

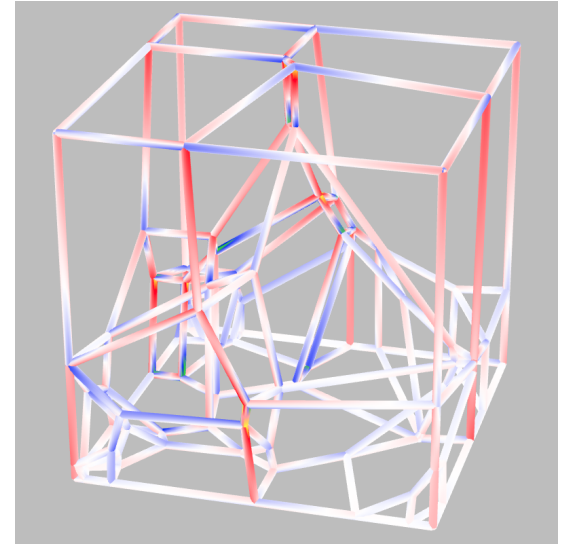

(c) Optimized Voronoi tessellation

Figure 2

a structural model. When building a structure, we usually aim for something which is light and stiff, saving on material cost while still preserving stability. For this reason, we compare the models in terms of mass and elastic energy, aiming for a minimum of both. Elastic energy can serve as a measure of stiffness, the resistance against deformation. It is given in $\mathrm{kNm}$. All tessellations are confined to a cube of $5 \mathrm{~m}$ length. Each steel-beam is modelled as a tube with a diameter of $114 \mathrm{~mm}$, and its walls have a thickness of $4 \mathrm{~mm}$. A uniformly distributed load is applied on top of the cube in negative z-direction, the points where the beams join on the xy-plane serve as supports.

For the initial Voronoi structure, we begin by randomly placing

$$
s \in\{10,20,30,40,50,75,100\}
$$

seeds within the cube to create the Voronoi cells. This is repeated 500 times, and elastic energy as well as mass are averaged for each $N$. Next, we create a triangle mesh by subdividing the cube into

$$
n \in\left\{2^{3}, 3^{3}, 4^{3}, 5^{3}, 6^{3}, 7^{3}, 8^{3}\right\}
$$

smaller cubes and splitting them into two tetrahedra. This way we can compare the irregular Voronoi tessellation to a triangle tessellation of similar mass. We chose this triangle mesh as being representative of a regular tessellation method.

Finally, we create random Voronoi cells with the same number of seeds as above, but this time we employ a genetic algorithm to find optimal positions for the seed points, minimizing both mass and elastic energy. To this end we use the multi-objective optimization package Octopus [11]. This introduces the Pareto principle for multiple goals.Octopus uses genome components as well as the objectives (mass and elastic energy) as input. We mod- elled the $\mathrm{x}, \mathrm{y}$, and $\mathrm{z}$ coordinates of the seed points as three genome components on the input side, which are further fed as input to the Karamba3D components creating the structural model. Mass and elastic energy, as calculated by the Karamba3D components, are then minimized by Octopus using a genetic algorithm. This means Octopus rearranges the $\mathrm{x}, \mathrm{y}$, and $\mathrm{z}$ coordinates of the input genomes, which in turn are used by Karamba3D to update the model. For optimization we need to pick a number of generations after which we stop the optimization process. Choosing a fixed number for all seeds gave an unfair advantage to the structures with a lower amount of seed points, as an optimal solution is found more quickly for a low amount of seeds. We instead set the number of generations to be twice the amount of seed points. This ensures that we can compare the results for a different amount of seeds. We then pick a solution on the Pareto front which satisfies both objectives equally well, by choosing the one closest to the bisector of the oriented coordinate axes. A better alternative would be to stop the optimization process when the optimal solution only shows a marginal change within a pre-defined timeframe. This, however, is not implemented as a standard feature in Octopus.

We now compare the models first by examining their structures visually in Fig. 2. The number of cells for the Voronoi structures is set to 20 . The subdivisions for the triangle mesh were set to 2 in order to arrive at a similar mass. Fig. 2 shows the utilization plot of the three models with the lower and upper threshold set to $20 \%$ and $80 \%$ of the minimum and maximum utilization respectively. The utilization is plotted uniformly between its extremes in red and blue. Values outside the range are colored in green or yellow. For the triangle mesh model one can see that the bending and axial deformation energy is strongest on the top of the structure where the load is applied. The bottom 


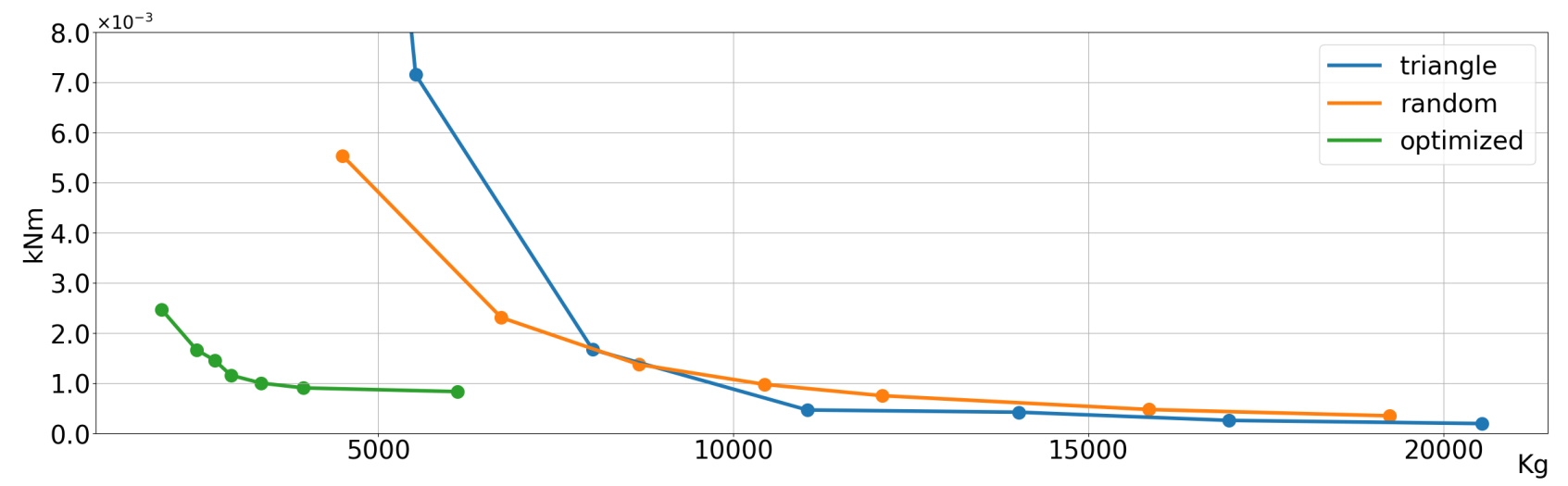

Figure 3: Comparison of elastic energy as a function of mass for random Voronoi structure, triangle mesh structure and optimized Voronoi structure. Random Voronoi has a lower elastic energy for lower number of seeds than the triangle mesh tessellation. Optimized Voronoi structure outperforms both in terms of weight.

part appears mostly rigid, which is in contrast with the random and optimized Voronoi structures. Here, higher deformation energy is present throughout the structures. However, the optimized structure shows this to a lesser extent than the random structure. This agrees with the plots in Fig. 3 described below. With regard to the triangle mesh, it should be noted that the larger angles found in the Voronoi structures make them easier to construct. A striking feature of the optimized Voronoi tessellation, is the apparent formation of a cupola-like structure in the lower parts of the cube, which distributes the load evenly. In Fig. 3 we compare the models by plotting their respective elastic energy as a function of their mass. Looking at triangle mesh and random Voronoi tessellation plots, we can see that for low subdivisions the triangle mesh shows a high elastic energy. Clearly the random Voronoi-modelled structure is superior for a lower mass. This changes at a mass around $9000 \mathrm{~kg}$. With more subdivisions the triangle structure is now more resistant to stress than the Voronoi structure of a similar mass. The optimized Voronoi structure is highly stable already at low mass. Comparing the mass of the three structures at an elastic energy of $0.001 \mathrm{kNm}$, for example, we see that the optimized structure weighs only approximately $1800 \mathrm{~kg}$ whereas the other two already have a mass of over $9000 \mathrm{~kg}$ at this point. Consequently, from a material utilization point of view, the triangle mesh is superior, whereas when aiming for light and rigid structures, the optimized Voronoi structure is preferable. The "bump" in the graph of the optimized Voronoi that can be seen at the point for 30 seeds (third from left) can be explained by a local optimum, where the genetic algorithm might not have found the true optimum after the respective number of generations. Owing to the random nature of the algorithm, the results generally may vary, but the general trend of the graph will remain the same.
To compare their performance in terms of weight and rigidity, we plot the models' respective elastic energy as a function of mass in Fig. 3 .

The plots generally show a trend towards low elastic energy the more mass ,i.e. beams are added. Comparing random and triangle mesh tessellation, we see that the random Voronoi outperforms the triangle mesh in terms of elastic energy up to a mass of about $9000 \mathrm{~kg}$. Heavier triangular structures, however, are more rigid than their Voronoi counterparts at approximately the same mass. The optimized Voronoi structures are much lighter than both random and triangle tessellation, while still retaining similar rigidity. For example, to reach an elastic energy of around $0.001 \mathrm{kNm}$ the optimized Voronoi structure weighs $1800 \mathrm{~kg}$, whereas random and triangular Voronoi structures have a mass of approximately $8600 \mathrm{~kg}$ and $8000 \mathrm{~kg}$ respectively at the same value for elastic energy.

To summarize: Random Voronoi structures give a good out-of-the-box solution when a low number of seeds is used and are comparable to regular triangle meshes. However, we can still optimize the position of the seeds to in turn create structures that clearly outperform triangle tessellations of similar weight.

\section{Related Work}

Finding that random Voronoi structures can still be improved by optimization processes, we have reviewed recent literature where structures can be manufactured or at least simulated by using Voronoi tessellation as an initial step before optimization. We identify two main areas where the structural properties of Voronoi diagrams are applicable: additive manufacturing and to a lesser extent architecture, where an important role is attributed to aesthetics, which is secondary to our interest. 


\subsection{Additive Manufacturing}

More commonly known as $3 \mathrm{D}$ printing is the process of constructing a 3D-model from a digital model. There are a number of different ways to achieve this, a popular one being fused filament manufacturing. Here a thermoplastic material is melted to iteratively build a 3D-model through the use of a movable nozzle. Generally speaking, the surveyed papers all deal with the infill pattern of models, as printing a solid model needlessly wastes material. Since a completely hollow object would not be very resistant to stress, however, an infill pattern is sought that minimizes material use and maximizes resistance to stress. To this end a variety of optimization strategies are employed to find an optimal positioning of the Voronoi seed cells. As we will see, it is also possible to achieve different kinds of elastic behaviour.

Öncel and Yaman [8] use topological optimization under specific load and support conditions and finite element analysis to define a number of density regions where the average stress is larger, and thus, more seeds need to be placed. This creates an infill pattern using hollow Voronoi cells. The objective of the optimization process is a pattern that minimizes the maximum deflection and mass of the printed object. They test their approach on three different models by comparing the performance of random Voronoi tessellation to their approach. The approach can be used in a given geometry, and the optimized Voronoi infill pattern exhibited higher mechanical performance than random Voronoi structures for the same model.

In a similar approach by Lu et al. [4], an optimal strengthto-weight ratio for 3D-printed objects is found by using irregular Voronoi diagrams for a hollowed interior structure. In order to find an optimal placement of the Voronoi cells, an initial stress map is computed. Additionally, the hollowing of the cells is maximized so that interior and exterior stresses can be sustained while minimizing the amount of material used.

A more biomimetic approach is given in Deering et al. [3]: Here, porous scaffolds are proposed to mimic the natural structure of trabecular bone by using Voronoi tessellation with selective seeding. Stress shielding effects, where an implant's high stiffness results in a stiffness discrepancy between surrounding bone and the implant, are an important factor for osseointegration. Since the geometry and size of the pores in the material influence the effects of stress on the scaffold, this approach aims to mimic the anisotropic network of struts and plates of trabecular bone. This is done by selectively placing Voronoi seeds on periodic planes within the volume. The resulting structure has a similar performance as the one measured in human bone. Contrary to the objectives of the papers before, in the work by Martinez et al. [5], the goal is a structure which exhibits elastic behaviour. Through the use of a polyhedral cone-like metric for the Voronoi diagram its geometry is changed. Varying the density, anisotropy, and angle of the design results in a graded elastic behaviour of the printed structure. This allows the printing of objects which can be both rigid and elastic in parts: for example, the creation of a cylinder which remains vertically rigid but allows for rotation in one direction. This is applicable to the design of prosthetics or wheels. Note that a rubber-like printing material is used in this case.

\subsection{Architecture}

To show whether the aforementioned properties of Voronoi-inspired techniques scale to larger structures, we survey approaches in the area of architecture. Since aesthetics play a larger role, the approaches are more limited. Mele et al. [6, 7] investigate the mechanical properties of irregular structural patterns as applied to tube configurations for tall buildings at macro-scale. The aim being to investigate properties of irregular patterns, with respect to constructability. In a first step, hexagonal patterns - nonregular patterns based fully on Voronoi diagrams, mixed regular patterns, and irregular patterns - are examined. Patterns generated from a regular hexagonal pattern are characterized by density degree and irregularity degree which can be varied along the building's height. The resulting Voronoi tube structure carries tributary gravity loads and total wind load. The mechanical properties of the Voronoibased structures were examined by representative volume elements-based approach. It was observed that irregular patterns are lighter, and the design procedure seemed useful for the initial design of such structures.

For use in the design of grid-shell structures, Pietroni et al. [9] propose a framework based on Voronoi diagrams which also exhibits good static performance, comparable to more conventional triangle or quad-based grid-shell structures. Using a finite element static analysis of the input surface, they create a stress tensor field according to which the tessellation's elements are sized and aligned. To account for aesthetics, they adapt the cell's geometry to form hexagons.

Common to the mentioned works is that Voronoi diagrams serve as an initial step in the design process but can be optimized towards fulfilling certain criteria. The Voronoi structure's properties of seed location, as well as the cells' size, orientation and geometry are due to change because of the optimization procedure. This approach scales from $3 \mathrm{D}$ printed objects to larger structures.

\section{Conclusion}

In this paper we have investigated the structural properties of Voronoi tessellations under stress, inspired by the occur- 
rence of similar patterns in nature. In a simple simulation, we have shown that random Voronoi diagrams can be used for the creation of structures which are rigid under applied load while being significantly lighter than a regular triangle mesh tessellation up to a certain point. These Voronoi structures can still be optimized by selective placement of

\section{References}

[1] F. Aurenhammer, Voronoi diagrams - a survey of a fundamental geometric data structure, ACM Computing Surveys (CSUR) 23(3) (1991), 345-405.

[2] A.M. Bronstein, M.M. Bronstein, R. KimMEL, Numerical geometry of non-rigid shapes, Springer Science \& Business Media, 2008.

[3] J. Deering, K.I. Dowling, L.-A. DiCecco, G.D. MCLEAn, B. YU, K. GRANDFIELD, Selective Voronoi tessellation as a method to design anisotropic and biomimetic implants, Journal of the Mechanical Behavior of Biomedical Materials 116 (2021), 104361 .

[4] L. Lu, A. Sharf, H. Zhao, Y. Wei, Q. Fan, X. Chen, Y. Savoye, C. Tu, D. Cohen-Or, B. CHEn, Build-to-last: Strength to weight 3D printed objects, ACM Transactions on Graphics 33(4) (2014), 1-10.

[5] J. Martínez, S. Hornus, H. Song, S. LefebVRE, Polyhedral Voronoi Diagrams for Additive Manufacturing, ACM Transaction on Graphics 37(4) (2018), 15.

[6] E. Mele, M. Fraldi, G. M. Montuori, G. PerRELLA, V.D. VISTA, Hexagrid-Voronoi transition in structural patterns for tall buildings, Frattura e Integrita Strutturale 13(47) (2019), 186-208.

[7] E. Mele, M. Fraldi, G. M. Montuori, G. PerRELLA, Non-conventional Structural Patterns for Tall Buildings: from Diagrid to Hexagrid and Beyond, Frattura e Integrita Strutturale (2016).

[8] A.C. ÖNCEL, U. YAMAN, Generation of optimized Voronoi based interior structures for improved mechanical properties, Procedia Manufacturing 38 (2019), 42-51. their seeds. We have surveyed papers where light and rigid structures are desired and identified two areas of application: additive manufacturing and to a lesser extent architecture. Voronoi structures give a good starting point, but their seed placement, cell-orientation, cell-size, cell-geometry can be further optimized to fulfil a stated objective.

[9] N. Pietroni, D. Tonelli, E. Puppo, M. Froli, R. Scopigno, P. Cignoni, Voronoi grid-shell structures, arXiv:1408.6591, (2014).

[10] C. Preisinger, Linking structure and parametric geometry, Architectural Design 83(2) (2013), 110 113.

[11] R. VIERLINGER, Octopus, https://www . food4rhino.com/en/app/octopus Accessed: 2021-08-10.

[12] G. VoronOI, Nouvelles applications des paramètres continus à la théorie des formes quadratiques. Deuxième mémoire. Recherches sur les parallélloèdres primitifs, Journal für die reine und angewandte Mathematik (Crelles Journal) 1908(134) (1908), 198-287.

\section{Leonard Weydemann}

e-mail: leonard.weydemann@uni-ak.ac.at

University of Applied Arts Vienna

Oskar-Kokoschka-Platz 2, A-1010 Vienna, Austria

\section{Christian Clemenz}

e-mail: christian.clemenz@uni-ak.ac.at

University of Applied Arts Vienna

Oskar-Kokoschka-Platz 2, A-1010 Vienna, Austria

\section{Clemens Preisinger}

orcid.org/0000-0002-0726-3335

e-mail: clemens.preisinger@uni-ak.ac.at

University of Applied Arts Vienna

Oskar-Kokoschka-Platz 2, A-1010 Vienna, Austria 